\title{
Socioeconomic Burdens of the COVID-19 Pandemic on LMIC Populations with Increased HIV Vulnerabilities
}

\author{
Leigh McClarty $^{1} \cdot$ Lisa Lazarus $^{1} \cdot$ Daria Pavlova ${ }^{2} \cdot$ Sushena Reza-Paul ${ }^{3,4} \cdot$ Olga Balakireva $^{2,5} \cdot$ Joshua Kimani $^{6,7}$. \\ Tetiana Tarasova ${ }^{2} \cdot$ Robert Lorway $^{1,3} \cdot$ Marissa L. Becker ${ }^{1,3,6} \cdot$ Lyle R. McKinnon $^{6,7,8}$
}

Accepted: 8 November 2021 / Published online: 25 November 2021

(c) The Author(s), under exclusive licence to Springer Science+Business Media, LLC, part of Springer Nature 2021

\begin{abstract}
Purpose of Review To review the impact of the COVID-19 pandemic and its public health response on key populations at risk of HIV infection, with a focus on sex workers.

Recent Findings Since last year several groups have documented how the COVID-19 pandemic has impacted the livelihoods and health of sex workers. We focus on case studies from Kenya, Ukraine, and India and place these in the broader global context of sex worker communities, drawing on common themes that span geographies.

Summary COVID-19-associated lockdowns have significantly disrupted sex work, leading to economic and health challenges for sex workers, ranging from HIV-related services to mental health and exposure to violence. Several adaptations have been undertaken by sex workers and frontline workers, including migration, a move to mobile services, and struggling to find economic supports. Strengthening community-based responses for future pandemics and other shocks is critical to safeguard the health of marginalized populations.
\end{abstract}

Keywords COVID-19 $\cdot$ HIV $\cdot$ Key populations $\cdot$ Community responses $\cdot$ Violence $\cdot$ Mental health

\section{Impact of the COVID-19 Pandemic: Beyond SARS-CoV-2 Infection}

COVID-19 has caused major global mortality, killing over four million individuals since late 2019 . While mortality may be decreasing in some areas due to better management

Leigh McClarty and Lisa Lazarus are co-first authors.

Marissa L. Becker and Lyle R. McKinnon are co-last authors.

This article is part of the Topical Collection on The Global Epidemic

Lyle R. McKinnon

lyle.mckinnon@umanitoba.ca

1 Institute for Global Public Health, Rady Faculty of Health Sciences, University of Manitoba, Winnipeg, Canada

2 Ukrainian Institute for Social Research After Oleksandr Yaremenko, Kyiv, Ukraine

3 Department of Community Health Sciences, Rady Faculty of Health Sciences, University of Manitoba, Winnipeg, Canada

4 Ashodaya Samithi, Mysuru, India and strengthened health systems including vaccine availability and uptake, the emergence of numerous variants with higher transmissibility, pathogenicity, and/or immune evasion highlights the dynamic nature of this pandemic. While the death toll is likely an undercount of deaths attributed to the causative agent, SARS-CoV-2, it also underestimates both additional deaths due to burden on healthcare systems (late cancer diagnoses, delayed surgeries, etc.), and broader health impacts of COVID-19 responses due to interruptions in healthcare and prevention services, as well as accompanying disruptions to daily life and income.

5 Institute for Economics and Forecasting, Ukrainian National Academy of Sciences, Kyiv, Ukraine

6 Department of Medical Microbiology and Infectious Diseases, University of Manitoba, 504-745 Bannatyne Ave, Winnipeg, MB R3E 0J9, Canada

7 Institute of Tropical and Infectious Diseases (UNITID), University of Nairobi, University of Nairobi, Nairobi, Kenya

8 Centre for the AIDS Programme of Research in South Africa (CAPRISA), Durban, South Africa 
Many individual-level risk factors for severe outcomes have been defined for SARS-CoV-2 infection. At the forefront is age; early reports confirmed a step-wise increase in mortality as shown from epi-centres such as China, Italy, and New York City. These have been borne out globally, with most studies showing mortality increasing exponentially by decade in those aged 50 years and above [1]. Male sex has been associated with increased mortality and altered inflammatory responses, whereas women have faced an increased burden of care work and domestic violence resulting from lockdown restrictions [2]. A wide range of comorbidities has been associated with severe COVID-19, many of which dampen the ability to respond to virus infection; these include cardiovascular disease, diabetes, obesity, kidney disease, cancer, and others [3].

In two recent meta-analyses, HIV infection was associated with modest increases in COVID-19 acquisition (25\% increase) and disease severity ( twofold increase) $[4,5]$. There is some heterogeneity in estimates that may depend on the population being studied; people living with HIV may be more likely to have co-morbidities that are proximal to severe SARS-CoV-2 presentation in the absence of HIV, and may be more critical in driving COVID-19 outcomes [6, 7]. In addition to biological factors that place individuals at higher risk for acquisition and severe disease, it is critical to acknowledge the contribution of overlapping social and structural factors contributing to both COVID-19 and HIV vulnerability [6-10]. For example, the ability to engage with recommended COVID-19 prevention measures is impacted by one's gender, socioeconomic status, employment, housing, and access to adequate sanitation [9-15].

While studying HIV-COVID-19 co-infection is relatively straightforward, few studies have examined the intersection between COVID-19 and those at risk of HIV transmission, who are often marginalized and prone to disruptions associated with both the pandemic and its public health measures [16]. Many of the structural and social factors creating vulnerability to COVID-19 are also key drivers of other health conditions; notably, the disproportionate HIV burden among key populations, including female, male, and transgender sex workers [17]. Numerous estimates suggest that HIV and other sexually transmitted and blood-borne infections (STBBI) incidence have increased during COVID-19 [18, 19]; these have a number of possible explanations, such as limited or disrupted access to prevention programmes, changing patterns of sex work and substance use, increased experiences of violence, and general disruptions in the lives of those at-risk of these infections.

Globally, those in lower socioeconomic strata have been more broadly affected by COVID-19 [7]. This is broadly true across multiple contexts, demonstrating that this phenomenon is not restricted to low- and middle-income countries (LMIC), per se. A common explanation is inability to socially distance due to living conditions, occupations not conducive to working from a distance, working in a service industry, and lacking financial protection measures that leave no choice but to work in a setting where exposure may be frequent. Importantly, however, LMIC tend to have relatively higher proportions of their populations that are unable to avoid COVID-19 exposure. These populations often overlap with those most vulnerable to HIV infection.

Initial COVID-19 predictions for LMIC were dire. In Africa, modelling predicted as many as 3.3 million COVID19 deaths [20]. While the latest waves comprised of variants of concern are causing more severe disease in many African countries, the initial COVID-19 waves in many LMIC did not observe a substantial burden of infection. While inadequate testing makes full scope of COVID-19 difficult to assess, serological surveillance studies have suggested widespread infection [21-24]. These data suggest, at least for the original pandemic strain, that a higher proportion of mild and/or asymptomatic SARS-CoV-2 infection occurred in this context. Despite the fact that this has been appreciated in retrospect, throughout much of 2020, a number of public health measures have been enacted in LMIC designed to stop COVID-19 transmission. Pandemic-specific public health orders such as "shelter-in place" measures, closures of "nonessential" businesses and schools, and reduced operations of health and social services have unanticipated, indirect consequences that are disproportionately experienced by marginalized groups $[9,10,14,25]$. The consequences of these public health orders have particularly affected sex work communities [26-29], and some restrictions have resulted in disruptions to essential services. While this has been experienced globally, the distribution of service disruptions has been uneven, with more significant disruption in LMICs [30]. Of significant relevance to sex worker communities are the disruptions in access to HIV prevention and care services, harm reduction supplies, and sexual and reproductive health resources [10, 31-36]. Compounded by the disruption in services [29, 31, 37, 38] and increased experiences of violence, stigma, discrimination, and economic hardships [10, 39], sex workers face increased HIV vulnerabilities during the pandemic. With a disproportionately high baseline HIV prevalence among sex workers [40-42], ensuring continued access to comprehensive HIV and STBBI services is of utmost importance. Violence, a known risk factor for HIV, has steadily increased across the globe since the beginning of the pandemic due to lockdown measures [43, 44]. Due to pervasive stigma and the criminalization of sex work, sex workers already experience heightened levels of violence in non-pandemic times [45, 46].

This review highlights how the COVID-19 pandemic and public health responses have impacted people in three LMIC countries where the authors live and/or work (India, Ukraine, and Kenya), with a particular focus on the experiences of sex 
workers and the frontline organizations providing health and social services to them throughout the pandemic. In each case study, we focus on immediate acute impacts, and what the lasting impact of the COVID-19 pandemic might be on HIV prevention and care in these settings.

\section{Case Study 1: India}

India confirmed its first reported case of COVID-19 on January 30, 2020 [47]. By March 25, the country imposed a 21-day lockdown that extended into June. The lockdown came with only $4 \mathrm{~h}$ warning, and while it was called "tough and timely" by the World Health Organization, it was also seen as extremely severe and punitive of those most vulnerable in the population, stranding millions of migrant workers in makeshift shelters, leaving approximately 400 million informal workers without income to face growing concerns about starvation [48, 49], and further entrenching social, political, religious, and economic divides across the country $[50,51]$.

Sex work has been greatly impacted by the pandemic lockdown and social distancing orders, with sex workers left out of government protection plans globally $[49,50]$. Reza-Paul et al. spoke with representatives from sex workers' organizations and their members across nine states in India about their experiences during the pandemic [52]. In these conversations, women highlighted their socioeconomic and mental health struggles. During the initial lockdown, which arrived at month's end, many sex workers struggled to pay rent. They no longer had income to send back home to their families in smaller villages and rural areas. Many chose to travel back to their familial homes, but faced further enforced quarantines and segregation due to fears over the virus. With few options for employment, many women then chose to return to larger cities. Alarming increases in violence and domestic abuse were also suffered by the women, whose husbands and boyfriends, employed as manual workers and drivers, were also impacted by unemployment and often coped by increasing their alcohol use. While some sex workers attempted to move towards selling sex online, this option did not prove viable for many women due to a lack of privacy and technology (also reported in [53]). While the country went through a four-phase "unlock" (i.e. a re-opening), sex workers continued to experience ongoing financial hardships. Some community-based organizations across the country attempted to support women in raising money to pay rent or money owed at their places of work, or help support attempts to start up alternative businesses, such as opening tea stalls, vegetable shops, or making sanitary napkins and masks, although these ventures rarely provided women with sufficient earnings. Sex workers were also left out of government support schemes; however, a major victory came when the Lawyers Collective won a challenge in the Supreme Court of India to allow sex workers to access dry food rations without requiring any form of identity card typically required to receive benefits $[52$, 54]. A second victory emerged following pressure from sex workers' rights networks that resulted in a \$10-million COVID-19 Emergency Response Mechanism for direct financial support for sex workers from the Global Fund to Fight AIDS, Tuberculosis and Malaria [55]. However, this fund amounts to a one-time direct bank transfer of a meagre 1500 INR (approximately \$20 USD), which has yet to be fully distributed due to procedural delays.

Building on years of community activism $[56,57]$, sex workers' organizations, such as Ashodaya Samithi based in Mysore, Karnataka, quickly adapted their experience in outreach and HIV prevention to respond to the emerging needs of their community [26]. When the district hospital, which was the main centre for antiretroviral therapy (ART) distribution, shifted gears to becoming a COVID-19 testing and treatment site, Ashodaya rapidly developed a communitybased ART delivery system in order to prevent disruption to treatment. They did this by drawing on their system of community healthcare navigators, who provide treatment support and have strong relationships with the district hospital, and by using their existing outreach strategy [26]. The response began in Mysore, but quickly expanded to other districts in the state, making ART available to individuals living with HIV outside of the sex work community who requested support. Tele-health services were developed to provide on-call support and counselling for sex workers and people living with HIV who were facing rises in stigma and discrimination and experiences of violence. WhatsApp groups and word-of-mouth were also used to ensure that sex workers were informed of and able to access all available government benefits, including dry rations, as well as to dispel misinformation about COVID-19. In addition, Ashodaya worked to mobilize local philanthropists, politicians, industry, and donor agencies to provide additional dry rations, medications for those with chronic ailments, masks, sanitizers, soaps, direct cash transfers for rent, cooking gas, school fees, and other utilities as required by the community [26].

In February 2021, the BBC posed the question of whether the pandemic was "finally coming to an end in India?" [58]. Despite these early expressions of hope, by the beginning of May, India was in the dire position of reaching over 20 million cases, facing overburdened health systems, a shortage of oxygen, and overwhelmed cremation sites, with the government facing extensive criticism for allowing very large gatherings at religious festivals and political rallies without social distancing or other prevention measures [59]. Sex workers also faced a tremendous loss with the passing of Dr. Smarajit Jana, the founder of the Durbar Mahila Samanwaya 
Committee, a renowned sex worker collective in Kolkata, and a tireless champion for sex workers' rights $[60,61]$. While the COVID-19 pandemic continues to greatly impact sex workers, sex workers' organizations in India adapted to meet the needs of their members, building on the lessons learned in HIV work and showing great resourcefulness and resilience $[26,52]$. As the world watches the alarming rise in cases [62], and ongoing COVID-19 restrictions continue to negatively impact sex workers [63], sex workers' organizations will again have to adapt their response to meet the emergent needs of their peers. With the state of Karnataka undergoing another lockdown in April 2021, Ashodaya again went back to their crisis mitigation mode of work by focusing on ART distribution, tele-health support, and ensuring basic supplies are reaching their community members.

\section{Case Study 2: Ukraine}

In March 2020, the Government of Ukraine imposed quarantine restrictions across the country, including in the conflictaffected area of eastern Ukraine. From September 2020, all oblasts (i.e., administrative divisions) have been categorized into one of four COVID-19 risk levels (red/orange/yellow/ green) based on two oblast-level indicators: COVID-19 incidence and hospital bed occupancy. These public health measures are implemented in cities and regions within oblasts according to their assessed COVID-19 risk levels. At the time of writing, the adaptive quarantine system has been extended until 30 June 2021 [64]. As of May 2021, Ukraine had reported more than 2 million COVID-19 cases and over 50,000 COVID-19-related deaths.

The pandemic has exposed various problems within the Ukrainian healthcare system that have been ignored for decades: insufficient public health infrastructure, gaps in social protection, and a general lack of preparedness to manage unforeseen public health emergencies [65]. Additionally, stigma related to the acquisition of COVID-19 has become an impediment to seeking testing and proper treatment and management among the general population in Ukraine. Moreover, the pandemic hit while Ukraine is in the midst of extensive reforms to its healthcare system [66, 67], which has further complicated access to essential healthcare services for the general population, and even more so for key populations, including sex workers. At any given time, sex workers (and others engaged in informal or "undeclared" work) in Ukraine have limited access to social protections and social services due to numerous, overlapping barriers [68], which further contribute to gaps in supports that are essential for addressing their specific needs during the pandemic [69]. In the context of COVID-19, sex workers and other key populations in Ukraine are now experiencing added barriers to accessing health and social services due to quarantine and changes in the mode of operation of many facilities providing services tailored to these populations' needs [67].

In March 2021, a virtual meeting was convened to explore the impact that the COVID-19 pandemic was having on sex work in Ukraine. The NGO "Ukrainian Institute for Social Research after Oleksandr Yaremenko" (UISR)—in partnership with the Institute for Global Public Health of the University of Manitoba (Canada), and with support from the Public Health Center of the Ministry of Health of Ukraineinvited stakeholders, including HIV service organizations from diverse and contextually distinct regions across the country, to discuss how the pandemic has impacted sex work practice and access to health and social services for sex workers. Organizations reported that decreased demand for sex services due to quarantine restrictions, closures of entertainment venues and restaurants, and job losses among clients all led to increased competition among sex workers, a general reduction in the cost of their services, and a decrease in income from sex work [70-73]. The pandemic also limited places where women could work. Organizations providing services for sex workers in eastern and central Ukraine reported that some women who worked in entertainment venues - such as cafés, restaurants, bars, and night clubsbegan working in highways and other street-based settings, or independently in apartments [71, 72]. Importantly, in Ukraine, highway- and apartment-based sex work environments are associated with characteristics that confer greater vulnerability to HIV for women who work there, compared to other venues [74]. Sex work practice on highways and in apartments is characterized by relatively high average client volume, and highway-based sex work has been specifically associated with higher reported rates of physical and sexual violence among women who work there [74].

According to service providers in the western and southern regions, border closures due to quarantine restrictions have resulted in noticeable decreases in the number of sex workers travelling abroad-to Poland, Turkey, and other Western European countries-for seasonal sex work. This has led to increased movement of sex workers within the country, with a particular influx in the west and south. During the pandemic, social workers and outreach workers reported that sex workers who had travelled domestically for work were not permitted to register with local women's clinics and were unable to access regular antenatal care $[72,73$, 75]. Furthermore, some service organizations were actively using mobile clinics to provide basic services (e.g. HIV testing and counselling) to sex workers, which were allowed under lockdown orders to continue operations during periods when access to other social and medical services was limited $[71,73,75]$. Mobile clinics enabled sex workers to continue accessing some basic health services in a way that mitigated 
their concerns around the risk of acquiring COVID-19. Unfortunately, the basic services offered through mobile outreach did not cover health services beyond HIV/STBBI prevention.

Despite national support for HIV prevention programmes-approximately 200 million UAH (7.4 million USD) in 2020 [67] — challenges presented by the pandemic highlight the need for additional structural changes to meet the healthcare needs of sex workers and other key populations. First and foremost, as COVID-19 continues to challenge the community, ongoing community assessments of emerging and persistent needs must be conducted, with an openness to restructuring HIV prevention programmes, as required. Furthermore, there is need for continued introduction of legislative changes regarding the regulation of sex work and healthcare; intensified advocacy for decriminalization of sex work, which would promote greater access to medical, legal, social, and financial protection services for sex workers; further development of a differentiated package of services for sex workers, taking into account their needs and the fact that in Ukraine, not only women but also men, transgender people, and people with different sexual orientations are involved in sex work.

Second, it is critical that programming within HIV service organizations is expanded to include systems for comprehensive documentation of and prompt response to violence, stigma, and discrimination and to provide adequate mental health supports for sex workers and members of other key populations (see, for example, Reza-Paul and colleagues [76]). Finally, successful programming must recognize the importance of providing sex workers the opportunity to access an expanded package of health and social services, including legal assistance, case management, and free medical examinations for HIV and STBBI. Exploring the possibility of expanding service delivery through mobile clinic platforms (beyond HIV/STBBI prevention) and introducing opportunities to provide online medical consulting services (tele-health) for sex workers in Ukraine may be important strategies for reducing barriers to broader health and social service access. At the same time, programmes should focus on expanding education and sensitization initiatives with service providers and police, working towards mitigating stigma and discrimination directed at sex workers.

\section{Case Study 3: Kenya}

Similar to other jurisdictions, SARS-CoV-2 infections were first detected in Kenya during March 2020 and resulted in swift implementation of public health measures. At the forefront of these was a curfew that impeded movement between $7 \mathrm{pm}$ and $5 \mathrm{am}$. While intended to minimize the economic impact on the daily trade economy, the nighttime closure of public places, including sex work hotspots, had a dramatic negative effect on the sex work industry, which continues until the time of writing. The economic hit of the pandemic and its restrictions, including massive loss of jobs in Kenya, means fewer paying clients for sex workers. Furthermore, the concept of social distancing led to a public health directive that there is "no safe sex with COVID", increasing stigma to sex workers as "disease transmitters", reminiscent of responses to the HIV pandemic. A few months into the curfew, many sex workers in Nairobi and elsewhere turned to social media platforms to increase their client volume in the absence of physical hotspots. However, this came with its own challenges, such as the increased risk of violence and insecurity associated with having sex in unexpected or less familiar places. Sex workers typically devote significant effort to controlling their environment to protect their security, including being "their sisters' keepers" within hotspots [77]. The need to move sex work to uncertain locations brings a multitude of challenges; at a client's place, sex workers have often been stranded overnight, with men demanding condomless sex, and charging room fees, thus negating any income gained. At the sex worker's residence, stigma increased, as neighbours became aware of their involvement in sex work. With their occupation identified, there were instances whereby members of the general community who continue to discriminate and stigmatize sex workers made sure the meagre social protection services channelled from the national government through the local administrators including the village chiefs did not reach them. This increased stigma, isolation, and vulnerability due to the rapid changes in sex work environments and practice placed increased stressors on what is often an already fragile existence. In Kisumu, survey data suggested that almost all sex workers knew about COVID-19, but only half showed concerns regarding acquisition. A reduction in clients and overall income was reported, in addition to sexual violence exposure, while access to HIV services were largely maintained [78]. This instability and economic hardship have led to notable reported increases in mental health challenges (including suicidal ideation), food insecurity, increased substance use (including the consumption of cheap and unsafe alcohol), and high rates of sexual and physical violence from clients, police, and others (resulting in serious injury and even deaths) [78].

In addition to the obvious toll on overall health, another important question is the extent to which these massive changes in sex work might influence HIV and STBBI transmission. Although clinics remained open to allow access to needed services and commodities, they have been heavily impacted by restrictions, with access decreasing for all services and limited clinical hours. Many sex workers reported lacking money for bus fare, airtime, data bundles and food. Among those on ARTs, poor adherence to medications 
was also reported since they could not take the drugs on an empty stomach. Many sex workers also fear contracting SARS-CoV-2 infection while at a crowded clinic (despite protocols in place to minimize transmission). Given these pressures, restrictions, and limited resources, many programmes have focused on maintaining HIV treatment for sex workers living with HIV infection, with less attention paid to prevention services. In some cases, communitybased organizations, for example those led by male sex workers, have filled this gap through innovative approaches to distributing HIV self-testing kits during the pandemic [79]. Other community collectives have used their support networks such as SWOP Ambassadors to fundraise for food and other basic necessities. The geographical aspects of the curfew are important, with most people not leaving their neighbourhood. In combination with the above changes to sex work practice, this could have dramatic effects on changing sexual networks. Despite this, in Nairobi there has been no obvious increase in HIV/STBBI incidence to date. Whether this is due to natural decline [80] or COVID-19 is uncertain, and if the decrease is due to economic reasons, there could be an increase in incidence following economic recovery, which needs to be monitored carefully [81].

The shock associated with COVID-19 restrictions is still being felt in the Nairobi sex work community, with sex workers re-learning to survive, often without many of their usual sources of support, which require face-to-face interactions with peers, sharing of resources, and programme access [82]. Due to the COVID-19 restrictions and fears, sex workers have been isolated and lost the benefits of the social capital derived from working at hotspots. Among these challenges there have been many cases of resilience, with some sex workers shifting to selling masks, sanitizer, washing clothes, domestic labour, etc., to make ends meet. However, even some of these jobs have become limited, as higher income families worry about COVID-19 risk associated with housekeepers who live in crowded settlements. Community-based organizations have endeavoured to provide support, in particular for lower socioeconomic sex workers in the form of donating money, food, and other resources. However, the growing need outstrips the available supplies. HIV programmes have invested significantly over the years in capacity building of peer leaders regarding HIV, but there was little time to prepare for COVID19. This led to serious confusion at the beginning where they had to pivot quickly and struggled to explain new and evolving COVID-19 concepts like "flatten the curve". There has also been a large burden on counsellors in HIV programmes, who must shift focus from HIV prevention to psychosocial issues and more general support. In some cases, sex workers have moved back to the village where basic needs such as food and housing insecurity are more readily met at a time of major economic burden. Finally, sex workers have demanded to be recognized as high risk workers who cannot maintain social distance, and for this reason should be prioritized for COVID-19 vaccination.

\section{Conclusions: Common Themes and the Way Forward}

While this review has focused on the specific contexts of India, Ukraine, and Kenya, the situation for sex workers and other key populations is not unique to these settings. Globally, there were calls at the start of the pandemic that the needs of sex workers must be considered in the response, highlighting issues of changing sex work patterns and how the most marginalized may feel the impact most acutely, further perpetuating their marginalization [83]. Numerous reports have highlighted how COVID19 and its accompanying responses have impacted sex workers in places ranging from the USA to Singapore to Thailand and beyond [84-87]. In Uganda, a revival of the link between truck drivers and sex workers in potentially spreading COVID-19, familiar to the early history of the HIV response, has been reported [88]. In addition, concerns around low literacy of sex workers, condom shortages, and an inability to access services including public health protective measures was raised, along with the possibility of riskier behaviours and a changing pattern of sex work [88]. One unintended consequence is the likelihood of being stopped by police intent on enforcing curfew rules, and the exposure to violence. A similar reduction in clients was observed in Zimbabwe, due to economic downturns leading to a decreased demand for sex work, along with preliminary speculation that a decrease in HIV/ STBBI risk may result [89]. Several perspectives have touched on issues of systemic and economic shocks, and the need for community empowerment and financial protection measures in dealing with these changes, in order that sex workers can emerge from this crisis in good health and better ready to deal with future shocks [90-93].

Several important lessons emerge from the experiences of key populations during the COVID-19 pandemic. Firstly, lockdowns and curfews may be necessary in a pandemic such as COVID-19, but are particularly challenging for groups such as those with highest HIV vulnerability. For key populations, the full impact of COVID-19 is not just about disease or even access to services, but also broader health equity issues that drive HIV susceptibility in the first place. Could these strategies be employed with greater precision? This type of approach was taken in India during the second wave, beginning in April 2021, in which microcontainment zones were implemented once a minimum threshold of COVID-19 cases were detected in a small, precisely defined geographic area, so as to minimize disruption 
to everyday life and economic activities. Secondly, it is important to consider what type of strategies can mitigate lockdown effects at community- and governmental-levels, and where responsibilities lie. Here, engagement of community-based and other non-governmental organizations in pandemic response and planning is critical to manage the mid- to longer-term impact of COVID-19 measures, such as oscillating public health restrictions that are difficult to predict and challenging, for many, to navigate. In each of our case studies and beyond, frontline workers in HIV programmes are invaluable resources and have taken on extra responsibilities to protect the most vulnerable during this challenging period. Finally, the need for financial protection measures and social supports cannot be ignored. The global economic impact of the pandemic has been immense; the economic consequences of the pandemic are particularly profound for sex workers, given that their main sources of income are primarily informal. Curfews and physical distancing measures have significantly affected the livelihoods of sex workers in many contexts around the world [29] and have drastically reduced their income [94]. In many countries, social protection measures have been put in place, including pandemic-specific financial supports, but these have not been extended equally to all groups. In particular, sex work is criminalized in many countries, and sex workers are routinely excluded from social protection programmes and other sources of emergency funds made available to other workers $[25,95,96]$. The extent of the disruption in health and social services and other indirect consequences, such as violence and income loss faced by sex workers, is yet to be fully understood. Going forward, it will continue to be important to promote and test quarantine strategies that include economic relief-ethical perspectives, advocating for social protections and supports that balance economic and health issues.

Historically, major systemic shocks, such as political conflict [97, 98], economic collapse [99, 100], and natural disasters [100-103] have worsened health inequities, disproportionately impacted vulnerable populations, and shaped HIV trajectories. The current COVID-19 pandemic is an important example of a global, systemic shock. Previous pandemics have also most impacted those who are marginalized in society [104]. Similarly, with COVID-19, LMICs and marginalized individuals within all countries tend to have the lowest COVID-19 vaccine access. This is critical as new global pandemics are almost certain to occur in the future [105] and we will continue to be faced with conflict, economic uncertainties, and disasters. Preparedness for these events is essential, but there is considerable variation in the ability of countries, and organizations, to respond to outbreaks and other systemic shocks [13, 101, 102]. An effective response requires transdisciplinary, multisectoral approaches with international collaboration to address complex public health emergencies and rapidly scale up responses [106-108]. Nearly 40 years of collective experience from HIV research has great potential to inform the public health response to the COVID-19 pandemic, with a specific focus on achieving equity in access to services and health outcomes [12, 106-108]. Evidence from the global HIV response highlights the necessity of meaningfully involving community to ensure that sex workers and other vulnerable groups are not left behind [108, 109].

\section{References}

1. Bonanad C, García-Blas S, Tarazona-Santabalbina F, Sanchis J, Bertomeu-González V, Fácila L, et al. The effect of age on mortality in patients with COVID-19: a meta-analysis with 611,583 subjects. J Am Med Dir Assoc. 2020;21:915-8.

2. Burki T. The indirect impact of COVID-19 on women. Lancet Infect Dis. 2020;20:904-5.

3. Ssentongo P, Ssentongo AE, Heilbrunn ES, Ba DM, Chinchilli VM. Association of cardiovascular disease and 10 other preexisting comorbidities with COVID-19 mortality: a systematic review and meta-analysis. PLoS ONE. Public Library of Science; 2020;15:e238215.

4. Mellor MM, Bast AC, Jones NR, Roberts NW, Ordóñez-Mena JM, Reith AJM, et al. Risk of adverse coronavirus disease 2019 outcomes for people living with HIV. AIDS. 2021;35:F1-10.

5. Ssentongo P, Heilbrunn ES, Ssentongo AE, Advani S, Chinchilli VM, Nunez JJ, et al. Epidemiology and outcomes of COVID19 in HIV-infected individuals: a systematic review and metaanalysis. Sci Rep. Nature Publishing Group; 2021;11:6283-312.

6. Raifman MA, Raifman JR. Disparities in the population at risk of severe illness from COVID-19 by race/ethnicity and income. Am J Prev Med. 2020;59:137-9.

7. Shadmi E, Chen Y, Dourado I, Faran-Perach I, Furler J, Hangoma $\mathrm{P}$, et al. Health equity and COVID-19: global perspectives. Int J Equity Health. BioMed Central; 2020;19:104-16.

8. Ahmad A, Chung R, Eckenwiler L, Ganguli-Mitra A, Hunt M, Richards R, et al. What does it mean to be made vulnerable in the era of COVID-19? Lancet. 2020;395:1481-2.

9. Lancet T. Redefining vulnerability in the era of COVID-19. Lancet. 2020;395:1089.

10. EpiC. Strategic considerations for mitigating the impact of COVID-19 on key-population-focused HIV programs: EpiC. 2020; <https://www.fhi360.org/sites/default/files/media/docum ents/epic-kp-strategic-considerationscovid-19.pdf $>$.

11. Corburn J, Vlahov D, Mberu B, Riley L, Caiaffa WT, Rashid SF, et al. Slum health: arresting COVID-19 and improving wellbeing in urban informal settlements. J Urban Health. Springer US; 2020;97:348-57.

12. Hargreaves J, Davey C. Group for lessons from pandemic HIV prevention for the COVID-19 response. Three lessons for the COVID-19 response from pandemic HIV. Lancet HIV. 2020;7:e309-11.

13. The Lancet Hiv. When pandemics collide. Lancet HIV. 2020;7:e301.

14. Wenham C, Smith J, Morgan R, Gender and COVID-19 Working Group. COVID-19: the gendered impacts of the outbreak. Lancet. 2020;395:846-8.

15. Pareek M, Bangash MN, Pareek N, Pan D, Sze S, Minhas JS, et al. Ethnicity and COVID-19: an urgent public health research priority. Lancet. 2020;395:1421-2. 
16. Lesko CR, Bengtson AM. HIV and COVID-19: intersecting epidemics with many unknowns. Am J Epidemiol. 2021;190:10-6.

17. UNAIDS. Miles to go - closing gaps, breaking barriers, righting injustices. Geneva: UNAIDS; 2018.

18. Balestri R, Magnano M, Rizzoli L, Infusino SD, Urbani F, Rech G. STIs and the COVID-19 pandemic: the lockdown does not stop sexual infections. J Eur Acad Dermatol Venereol. John Wiley \& Sons, Ltd; 2020;34:e766-8.

19. Heerfordt IM. STIs during the first and second wave of COVID-19 in Denmark. Sex Transm Infect; 2021. Online ahead of print.

20. Coronavirus in Africa: How deadly could COVID-19 become? https://www.dw.com/en/coronavirus-in-africa-how-deadlycould-covid-19-become/a-53230519 Accessed May 1, 2020.

21. Mulenga LB, Hines JZ, Fwoloshi S, Chirwa L, Siwingwa M, Yingst S, et al. Prevalence of SARS-CoV-2 in six districts in Zambia in July, 2020: a cross-sectional cluster sample survey. Lancet Glob Health. 2021;9:e773-81.

22. Shaw JA, Meiring M, Cummins T, Chegou NN, Claassen C, Du Plessis N, et al. Higher SARS-CoV-2 seroprevalence in workers with lower socioeconomic status in Cape Town. South Africa PLoS ONE. Public Library of Science; 2021;16:e0247852.

23. Adetifa IMO, Uyoga S, Gitonga JN, Mugo D, Otiende M, Nyagwange J, et al. Temporal trends of SARS-CoV-2 seroprevalence in transfusion blood donors during the first wave of the COVID-19 epidemic in Kenya. medRxiv. Cold Spring Harbor Laboratory Press; 2021;2021.02.09.21251404.

24. Chibwana MG, Jere KC, Kamn'gona R, Mandolo J, KatungaPhiri V, Tembo D, et al. High SARS-CoV-2 seroprevalence in Health Care Workers but relatively low numbers of deaths in urban Malawi. medRxiv. Cold Spring Harbor Laboratory Preprints; 2020.

25. Human Rights Watch. India: COVID--. Lockdown puts poor at risk. 2020; a wide array of https://www.hrw.org/news/2020/03/ 27/india-covid-19-lockdown-puts-poor-risk. Accessed 27 April 2020, 2020

26. Reza-Paul S, Lazarus L, Haldar P, Reza Paul M, Lakshmi B, Ramaiah M, et al. Community action for people with HIV and sex workers during the COVID-19 pandemic in India. WHO South East Asia. J Public Health. 2020;9:104-6.

27. Jozaghi E, Bird L. COVID-19 and sex workers: human rights, the struggle for safety and minimum income. Can J Public Health. Springer International Publishing; 2020;111:406-7.

28. Gichuna S, Hassan R, Sanders T, Campbell R, Mutonyi M, Mwangi P. Access to healthcare in a time of COVID-19: sex workers in crisis in Nairobi, Kenya. Glob Public Health. Taylor \& Francis; 2020;15:1430-42.

29. Kimani J, Adhiambo J, Kasiba R, Mwangi P, Were V, Mathenge $\mathrm{J}$, et al. The effects of COVID-19 on the health and socioeconomic security of sex workers in Nairobi, Kenya: Emerging intersections with HIV. Glob Public Health. Taylor \& Francis; 2020;15:1073-82.

30. World Health Organization. Pulse survey on continuity of essential health services during the COVID-19 pandemic. Interim report. Geneva: World Health Organization; 2020.

31. UNAIDS. Assessing the needs of young key populations during COVID-19 outbreak in Asia and the Pacific. 2020; https:// unaids-ap.org/2020/04/30/assessing-the-needs-of-young-keypopulations-during-covid-19-outbreak-in-asia-and-the-pacif icl. Accessed 5 May, 2020.

32. Tran NT, Tappis H, Spilotros N, Krause S, Knaster S, InterAgency Working Group on Reproductive Health in Crises. Not a luxury: a call to maintain sexual and reproductive health in humanitarian and fragile settings during the COVID-19 pandemic. Lancet Glob Health. 2020;8:e760-1.
33. Shoptaw S, Goodman-Meza D, Landovitz RJ. Collective call to action for HIV/AIDS community-based collaborative science in the era of COVID-19. AIDS Behav. Springer US; 2020;24:2013-6.

34. Jiang H, Zhou Y, Tang W. Maintaining HIV care during the COVID-19 pandemic. Lancet HIV. 2020;7:e308-9.

35. Tang K, Gaoshan J, Ahonsi B, Ali M, Bonet M, Broutet N, et al. Sexual and reproductive health (SRH): a key issue in the emergency response to the coronavirus disease (COVID- 19) outbreak. Reprod Health. BioMed Central; 2020;17:59-63.

36. UNFPA. Impact of the COVID-19 pandemic on family planning and ending gender-based violence, female genital mutilation and child marriage: UNFPA. 2020; <https://www.unfpa.org/ resources/impact-covid-19-pandemic-family-planning-and-ending-genderbased-violence-female-genital $>$.

37. The Lancet Hiv. Lockdown fears for key populations. Lancet HIV. 2020;7:e373.

38. Verster A, Macdonald V, Luhmann N. WHO guidance on COVID-19 specific to key populations. Key populations: Evidence in action webinar series: LINKAGES and EpiC; 2020.

39. Ayala G. COVID-19 and its impact of key populations: A community reflection. Key populations: Evidence in action webinar series: LINKAGES and EpiC. 2020; <https://mcusercontent. com/017a363ed67b2aa8d9ffcaa4a/files/f93c37e7-b302-442089b9-2a4efacc2efc/COVID_19_Impact_on_KPs_Community_ Reflection_040620.pdf>.

40. Shannon K, Strathdee SA, Goldenberg SM, Duff P, Mwangi P, Rusakova M, et al. Global epidemiology of HIV among female sex workers: influence of structural determinants. Lancet. 2015;385:55-71.

41. Baral S, Beyrer C, Muessig K, Poteat T, Wirtz AL, Decker MR, et al. Burden of HIV among female sex workers in low-income and middle-income countries: a systematic review and metaanalysis. Lancet Infect Dis. 2012;12:538-49.

42. Oldenburg CE, Perez-Brumer AG, Reisner SL, Mattie J, Bärnighausen T, Mayer KH, et al. Global burden of HIV among men who engage in transactional sex: a systematic review and meta-analysis. PLoS ONE. 2014;9:e103549.

43. Leslie E, Wilson R. Sheltering in place and domestic violence: evidence from calls for service during COVID-19. J Public Econ. 2020;189:104241.

44. Mlambo-Ngcuka P. Violence against women and girls: the shadow pandemic. 2020; https://www.unwomen.org/en/news/ stories/2020/4/statement-ed-phumzile-violence-against-womenduring-pandemic. Accessed 19 June 2021.

45. Deering KN, Amin A, Shoveller J, Nesbitt A, Garcia-Moreno C, Duff P, et al. A systematic review of the correlates of violence against sex workers. Am J Public Health. American Public Health Association; 2014;104:e42-54.

46. Shannon K, Csete J. Violence, condom negotiation, and HIV/STI risk among sex workers. JAMA. American Medical Association; 2010;304:573-4.

47. Andrews MA, Areekal B, Rajesh KR, Krishnan J, Suryakala R, Krishnan B, et al. First confirmed case of COVID-19 infection in India: a case report. Indian J Med Res. 2020;151:490-2.

48. Lancet T. India under COVID-19 lockdown. Lancet. 2020;395:1315.

49. Sardar S, Abdul-Khaliq I, Ingar A, Amaidia H, Mansour N. COVID-19 lockdown: a protective measure or exacerbator of health inequalities? A comparison between the United Kingdom and India. a commentary on "the socio-economic implications of the coronavirus and COVID-19 pandemic: A review." Int J Surg. 2020;83:189-91.

50. Mukherjee S. Disparities, desperation, and divisiveness: Coping with COVID-19 in India. Psychol Trauma. 2020;12:582-4. 
51. Golechha M. COVID-19, India, lockdown and psychosocial challenges: What next? Int J Soc Psychiatry. SAGE Publications Sage UK: London, England; 2020;66:830-2.

52. Reza-Paul S, Kumar PN, Lazarus L, Reza Paul M, Pasha A, Ramaiah M, Lorway R, Sundararaman S. From vulnerability to resilience: sex workers fight COVID-19. In: Pachauri S, Pachauri A, editors. Health dimensions of COVID-19 in India and Beyond. Singapore: Springer Nature Singapore Pte Ltd; 2021. [In Press].

53. Singh B, Vashisht. COVID-19 and conflict: why virtual sex work hasn't helped sex workers in India survive the COVID-19 lockdown. Bliss: International Institute of Social Studies, Erasmus University Rotterdam. 2021. https://issblog.nl/2021/01/22/covid19-and-conflict-why-virtual-sex-work-hasnt-helped-sex-workersin-india-survive-the-covid-19-lockdown/. Accessed 16 May 2021.

54. Talwar S. SC directs states to provide dry rations for identified sex workers sans insistence on identity proof $\&$ file affidavit on benefits accrued. Live Law. 2020. https://www.livelaw.in/top-stories/ mode-of-entry-in-service-promotion-of-persons-with-disabilitiessupreme-court-176530?infinitescroll=1. Accessed 16 May 2021.

55. Reza-Paul, S. From vulnerability to resilience: The story of a sex worker organization in managing community health. Presentation at the Ukrainian Institute for Social Research after Oleksandr Yaremenko and Institute for Global Public Health online discussion on "Specifics of policymaking to address HIV/STBBI among commercial sex workers and their clients in the complex contexts of conflict and the pandemic'. 2021. http://uisr.org.ua/ news/36/184.html: Ukrainian Institute for Social Research after Oleksandr Yaremenko 2021. Accessed 16 May 2021.

56. Jana S, Basu I, Rotheram-Borus MJ, Newman PA. The Sonagachi Project: a sustainable community intervention program. AIDS Educ Prev. Guilford Publications Inc; 2004;16:405-14.

57. Reza-Paul S, Beattie T, Syed HUR, Venukumar KT, Venugopal MS, Fathima MP, et al. Declines in risk behaviour and sexually transmitted infection prevalence following a community-led HIV preventive intervention among female sex workers in Mysore. India AIDS. 2008;22(Suppl 5):S91-100.

58. Biswas S. Coronavirus: is the epidemic finally coming to an end in India? BBC News. 2021. https://www.bbc.com/news/worldasia-india-56037565. Accessed 16 May 2021.

59. Lancet T. India's COVID-19 emergency. Lancet. 2021;397:1683.

60. Kapoor N. UNAIDS saddened by the death of Smarajit Jana. UNAIDS. 2021. https://www.unaids.org/en/resources/presscentre/featurestories/2021/may/20210510_smarajit-jana. Accessed 16 May 2021.

61. Ghose T. A voice for sex workers. The Indian Express. 2021. https://indianexpress.com/article/opinion/a-voice-for-sex-worke rs-dr-smarajit-jana-hiv-aids-7311047/. Accessed 16 May 2021.

62. Serhan Y. Why the world should worry about India. The Atlantic. 2021. https://www.theatlantic.com/international/archive/2021/ 04/india-covid-19-crisis/618691/. Accessed 16 May 2021.

63. Anand J. Night and weekend curfews spell trouble for sex workers. The Hindu. 2021. https://www.thehindu.com/news/cities/ Delhi/night-and-weekend-curfews-spell-trouble-for-sex-worke rs/article34347247.ece. Accessed 16 May 2021.

64. UNOCHA. Ukraine: Situation Report. New York: United Nations Office for the Coordination of Humanitarian Affairs; 2021.

65. United Nations Ukraine. Assessment of the Socio-Economic Impact of COVID-19 in Ukraine. Kyiv: United Nations; 2020.

66. European Asylum Support Office. Ukraine FFM report - Healthcare Reform and Economic Accessibility: Medical Country of Origin Information Report. Valetta, Malta: EASO, 2021.

67. Alliance for Public Health, \#SoS_project 2021, Matahari. COVID-19 response and impact on HIV and TB services, 2021.

68. Libanova E, Makarova O, Cherenko L, Tkachenko L, Palii O. Social protection and social inclusion in Ukraine. Kyiv: Ukrainian Centre for Social Reforms, 2009.
69. Tarasova Т. Бар'єри та проблеми доступу до медикосоціальних послуг секс-працівників в Україні [Barriers and problems of access to medical and social services among sex wokrers in Ukraine]. Presentation at the Ukrainian Institute for Social Research after Oleksandr Yaremenko and Institute for Global Public Health online discussion on "Specifics of policymaking to address HIV/STBBI among commercial sex workers and their clients in the complex contexts of conflict and the pandemic". 2021. http://uisr.org.ua/news/36/184.html: Ukrainian Institute for Social Research after Oleksandr Yaremenko 2021. Accessed 2 June 2021.

70. Sharapova А. Благодійна організація "Харківський благодійний фонд “Благо” [Charitable organization "Kharkiv charitable fund Blago"]. Presentation at the Ukrainian Institute for Social Research after Oleksandr Yaremenko and Institute for Global Public Health online discussion on 'Specifics of policymaking to address HIV/STBBI among commercial sex workers and their clients in the complex contexts of conflict and the pandemic'. 2021. http://uisr.org.ua/news/36/184.html: Ukrainian Institute for Social Research after Oleksandr Yaremenko; 2021. Accessed 2 June 2021.

71. Bondarenko М. Вплив пандемії COVID-19 на сферу сексбізнесу в Полтавській області: БО «Світло надії» [The impact of the COVID-19 pandemic on sex business in the Poltava oblast: Charitable Organization "Light of hope"]. Presentation at the Ukrainian Institute for Social Research after Oleksandr Yaremenko and Institute for Global Public Health online discussion on 'Specifics of policymaking to address HIV/STBBI among commercial sex workers and their clients in the complex contexts of conflict and the pandemic'. 2021. http://uisr.org.ua/news/36/ 184.html: Ukrainian Institute of Social Research after Oleksandr Yaremenko; 2021. Accessed 2 June 2021.

72. Semikop T. Вплив пандемії COVID-19 на сферу секс-бізнесу в м. Одеса [The impact of the COVID-19 pandemic on sex business in Odessa]. Presentation at the Ukrainian Institute for Social Research after Oleksandr Yaremenko and Institute for Global Public Health online discussion on "Specifics of policymaking to address HIV/STBBI among commercial sex workers and their clients in the complex contexts of conflict and the pandemic". 2021. http://uisr.org.ua/news/36/184.html: Ukrainian Institute of Social Research after Oleksandr Yaremenko; 2021. Accessed 2 June 2021.

73. Dotsenko N. Благодійна організація «Благодійний фонд «Сподівання» [Charitable organization «Charitable foundation «Spodivannya»]. Presentation at the Ukrainian Institute for Social Research after Oleksandr Yaremenko and Institute for Global Public Health online discussion on "Specifics of policymaking to address HIV/STBBI among commercial sex workers and their clients in the complex contexts of conflict and the pandemic". 2021. http://uisr.org.ua/news/36/184.html: Ukrainian Institute for Social Research after Oleksandr Yaremenko; 2021. Accessed 2 June 2021.

74. Cheuk E, Leung S, Balakireva O, et al. Risk and place: The association between hotspot typology and determinants of HIV risk among female sex workers in Ukraine. STI \& HIV 2019 World Congress 2019. Vancouver, Canada; 2019.

75. Makarenko О. Особливості надання секс-послуг у Волинській області [Specifics of sex work in Volyn oblast]. Presentation at the Ukrainian Institute for Social Research after Oleksandr Yaremenko and Institute for Global Public Health online discussion on "Specifics of policymaking to address HIV/STBBI among commercial sex workers and their clients in the complex contexts of conflict and the pandemic". 2021. http://uisr.org.ua/news/36/ 184.html: Ukrainian Institute for Social Research after Oleksandr Yaremenko; 2021. Accessed 2 June 2021.

76. Reza-Paul S, Lorway R, O’Brien N, Lazarus L, Jain J, Bhagya $\mathrm{M}$, et al. Sex worker-led structural interventions in India: a 
case study on addressing violence in HIV prevention through the Ashodaya Samithi collective in Mysore. Indian J Med Res. Wolters Kluwer -- Medknow Publications; 2012;135:98-106.

77. Lorway R, Lazarus L, Chevrier C, Khan S, Musyoki HK, Mathenge J, et al. Ecologies of security: On the everyday security tactics of female sex workers in Nairobi, Kenya. Glob Public Health. Taylor \& Francis; 2018;13:1767-80.

78. Mantell JE, Franks J, Lahuerta M, Omollo D, Zerbe A, Hawken $M$, et al. Life in the balance: young female sex workers in Kenya weigh the risks of COVID-19 and HIV. AIDS Behav. Springer US; 2021;25:1323-30.

79. Odinga MM, Kuria S, Muindi O, Mwakazi P, Njraini M, Melon $\mathrm{M}$, et al. HIV testing amid COVID-19: community efforts to reach men who have sex with men in three Kenyan counties. Gates Open Res. F1000 Research Limited; 2020;4:117.

80. Tago A, McKinnon LR, Wanjiru T, Muriuki F, Munyao J, Gakii $\mathrm{G}$, et al. Declines in HIV prevalence in female sex workers accessing an HIV treatment and prevention programme in Nairobi, Kenya over a 10-year period. AIDS. 2021;35:317-24.

81. Callander D, Meunier É, DeVeau R, Grov C, Donovan B, Minichiello $\mathrm{V}$, et al. Sex workers are returning to work and require enhanced support in the face of COVID-19: results from a longitudinal analysis of online sex work activity and a content analysis of safer sex work guidelines. Sex Health. CSIRO PUBLISHING; 2020;17:384-6.

82. Macharia P, Moore S, Mathenge J, Ndunda E, Lazarus L, McKinnon LR, et al. Sexual health among Kenyan male sex workers in a time of COVID-19: Health Education Journal. London: SAGE Publications Sage UK; 2020.

83. Platt L, Elmes J, Stevenson L, Holt V, Rolles S, Stuart R. Sex workers must not be forgotten in the COVID-19 response. Lancet. 2020;396:9-11.

84. Tan RKJ, Lim JM, Lo JJ-M, Teo AKJ, O'Hara CA, Ching AH, et al. Conducting rapid qualitative research to support sex workers' health and social needs in the face of COVID-19: capitalising on stakeholder networks from the HIV response in Singapore to drive policymaking. Sex Transm Infect. BMJ Publishing Group Ltd; 2021;97:84-4.

85. Rogers BG, Paradis-Burnett A, Nagel K, et al. Sex workers and syndemics: A population vulnerable to HIV and COVID-19. Arch Sex Behav 2021; 50(5): 2007-16

86. Singer R, Crooks N, Johnson AK, Lutnick A, Matthews A. COVID-19 prevention and protecting sex workers: a call to action. Arch Sex Behav. Springer US; 2020;49:2739-41.

87. Janyam S, Phuengsamran D, Pangnongyang J, Saripra W, Jitwattanapataya L, Songsamphan C, et al. Protecting sex workers in Thailand during the COVID-19 pandemic: opportunities to build back better. WHO South East Asia J Public Health. Medknow Publications; 2020;9:100-3.

88. Kawala BA, Kirui BK, Cumber SN. Why policy action should focus on the vulnerable commercial sex workers in Uganda during COVID-19 fight. Pan Afr Med J. 2020;35:102.

89. Machingura F, Chabata ST, Busza J, et al. Potential reduction in female sex workers' risk of contracting HIV during coronavirus disease 2019. AIDS 2021; 35(11): 1871-2.

90. Iversen J, Sabin K, Chang J, Morgan-Thomas R, Prestage G, Strathdee SA, et al. COVID-19, HIV and key populations: crosscutting issues and the need for population-specific responses. J Int AIDS Soc. John Wiley \& Sons, Ltd; 2020;23:e25632.

91. Jacobson L, Regan A, Heidari S, Onyango MA. Transactional sex in the wake of COVID-19: sexual and reproductive health and rights of the forcibly displaced. Sex Reprod Health Matters. Taylor \& Francis; 2020;28:1822493.

92. Callander D, Meunier É, DeVeau R, Grov C, Donovan B, Minichiello $\mathrm{V}$, et al. Investigating the effects of COVID-19 on global male sex work populations: a longitudinal study of digital data. Sex Transm Infect. BMJ Publishing Group Ltd; 2021;97:93-8.

93. Adebisi YA, Alaran AJ, Akinokun RT, Micheal AI, Ilesanmi EB, Lucero-Prisno DE. Sex workers should not be forgotten in Africa's COVID-19 response. Am J Trop Med Hyg. 2020;103:1780-2.

94. Global Network of Sex Work Projects. Impact of COVID-19. 2020; https://www.nswp.org/page/covid-19?fbclid=IwAR02 aLf01ZxUJN6jttKdihjtvV_JqhS1 sx15hRasUsUvS5pKzigq e7Ccoc. Accessed September 28, 2020.

95. Joint Statement: Sex workers must not be left behind in the response to COVID-19 [press release]. Geneva: UNAIDS; 2020.

96. Chakraborty R, Ramaprasad H. "They are starving": women in India's sex industry struggle for survival. The Guardian. 2020.

97. Spiegel PB, Bennedsen AR, Claass J, Bruns L, Patterson N, Yiweza D, et al. Prevalence of HIV infection in conflict-affected and displaced people in seven sub-Saharan African countries: a systematic review. Lancet. 2007;369:2187-95.

98. Vasylyeva TI, Liulchuk M, Friedman SR, Sazonova I, Faria NR, Katzourakis A, et al. Molecular epidemiology reveals the role of war in the spread of HIV in Ukraine. Proc Natl Acad Sci U S A. National Academy of Sciences; 2018;115:1051-6.

99. Claborn DM. A Narrative review of the role of economic crisis on health and healthcare infrastructure in three disparate national environments. Int J Environ Res Public Health. Multidisciplinary Digital Publishing Institute; 2020;17:1252.

100. Alam K, Mahal A. Economic impacts of health shocks on households in low and middle income countries: a review of the literature. Glob Health. BioMed Central; 2014;10:21-18.

101. Raker EJ, Zacher M, Lowe SR. Lessons from Hurricane Katrina for predicting the indirect health consequences of the COVID19 pandemic. Proc Natl Acad Sci U S A. National Academy of Sciences; 2020;117:12595-7.

102. Low AJ, Frederix K, McCracken S, Manyau S, Gummerson E, Radin E, et al. Association between severe drought and HIV prevention and care behaviors in Lesotho: a population-based survey 2016-2017. PLoS Med. Public Library of Science; 2019;16:e1002727.

103. Benach J, Díaz MR, Muñoz NJ, Martínez-Herrera E, Pericàs JM. What the Puerto Rican hurricanes make visible: chronicle of a public health disaster foretold. Soc Sci Med. 2019;238:112367.

104. Wade L. From Black Death to fatal flu, past pandemic show why people on the margins suffer most: Inequality made historical pandemics 'worse than they had to be'. Science. 2020; <https:// www.science.org/content/article/black-death-fatal-flu-past-pande mics-show-why-people-marginssuffer-most $>$.

105. Morens DM, Fauci AS. Emerging pandemic diseases: how we got to COVID-19. Cell. 2020;182:1077-92.

106. Oppenheim B, Gallivan M, Madhav NK, Brown N, Serhiyenko $\mathrm{V}$, Wolfe ND, et al. Assessing global preparedness for the next pandemic: development and application of an Epidemic Preparedness Index. BMJ Glob Health. 2019;4:e001157.

107. Jacobsen KH. Will COVID-19 generate global preparedness? Lancet. 2020;395:1013-4.

108. Davies AR, Homolova L, Grey CNB, Bellis MA. Health and mass unemployment events-developing a framework for preparedness and response. J Public Health (Oxf). 2019;41:665-73.

109. UNAIDS. Rights in the time of COVID-19: Lessons from HIV for an effective, community led response. Geneva: UNAIDS. 2020; <https://www.unaids.org/en/resources/documents/2020/ human-rights-andcovid-19>.

Publisher's Note Springer Nature remains neutral with regard to jurisdictional claims in published maps and institutional affiliations. 